\title{
EVALUASI FAKTOR-FAKTOR SUKSES SISTEM INFORMASI RUMAH SAKIT PADA RUMAH SAKIT XYZ MENGGUNAKAN MODEL DELONE \& MCLEAN
}

\section{EVALUATION OF SUCCESS FACTORS IN HOSPITAL INFORMATION SYSTEM AT XYZ HOSPITAL USING DELONE \& MCLEAN MODELS}

\author{
Miftah Muhammad ${ }^{1}$, Assaf Arief $^{2}$ \\ ${ }^{12}$ Fakultas Teknik, Program Studi Teknik Informatika \\ Universitas Khairun, Ternate \\ Email:miftahmuh@gmail.com
}

\begin{abstract}
Abstrak
Rumah Sakit XYZ sebagai salah satu lembaga pemerintah, saat ini sedang berupaya untuk mentransformasikan pelayanannya guna meningkatkan kepuasan pasien dengan menerapkan sistem informasi rumah sakit. Namun, dalam penerapannya selama setahun, banyak keluhan terkait sistem baru tersebut. Penelitian ini bertujuan untuk mengetahui faktor sukses yang mempengaruhi kepuasan pengguna dan manfaat yang dirasakan oleh pengguna di RS XYZ dengan menggunakan model sukses Delone McLean. Pengumpulan data yang dibutuhkan dilakukan dengan serangkaian kuesioner yang dikembangkan sesuai model. PLS-SEM digunakan untuk menguji model penelitian dengan software Smart PLS 3.0. Manfaat penelitian ini mengacu pada manfaat yang dirasakan pengguna saat menggunakan sistem informasi rumah sakit dalam hal membantu pengguna dalam meningkatkan efisiensi dan efektifitas dalam melakukan aktivitasnya. Hasil penelitian terhadap 75 responden menunjukkan bahwa penggunaan sistem, kepuasan pengguna, dan faktor organisasi berpengaruh terhadap keuntungan yang dirasakan, sedangkan kualitas informasi, kualitas sistem, dan kualitas layanan berpengaruh signifikan terhadap penggunaan sistem informasi, namun hanya kualitas informasi dan penggunaan sistem yang berpengaruh signifikan berpengaruh pada kepuasan pengguna. Hasil penelitian ini dapat menjadi masukan bagi RS XYZ untuk memperbaiki sistem informasinya kedepannya.
\end{abstract}

\section{Kata Kunci: Sistem Informasi Rumah Sakit, Model Sukses, Delone McLean.}

\begin{abstract}
XYZ Hospital, as a government agency is currently trying to transform its services to increase patient satisfaction by implementing a hospital information system. However, in its implementation for a year, there were many complaints
\end{abstract}


regarding the new system. This study aims to determine the success factors that affect user satisfaction and the benefits felt by users at XYZ Hospital by using the Delone success model. Data collection is done with a series of questionnaires developed according to the model. PLS-SEM is used to test the research model with Smart PLS 3.0 software. The benefits of this study refer to the benefits felt by users when using hospital information systems in terms of helping users to increase efficiency and effectiveness in carrying out their activities. The results of 75 respondents showed that system use, user satisfaction, and organizational factors affected perceived benefits. In contrast, information quality, system quality, and service quality had a significant effect on the use of information systems. However, only the quality of information and system use had a significant effect on user satisfaction. The results of this study can be used as suggestions for XYZ Hospital to improve its information system in the future.

\section{Keywords: Hospital Information System, Delone McLean IS Success model}

\section{PENDAHULUAN}

Penggunaan Teknologi Informasi dan Komunikasi (TIK) untuk memberikan nilai kepada pengguna dalam berbisnis telah terbukti memberikan manfaat yang luar biasa antara lain peningkatan produktivitas, efisiensi, peningkatan layanan kepada pelanggan dan peningkatan peluang bisnis. Dampak positif TIK dalam dunia bisnis saat ini sedang dilakukan oleh instansi pemerintah yang bertujuan untuk meningkatkan pelayanan kepada masyarakat secara lebih efektif dan efisien [1], [2].

Rumah Sakit XYZ yang berlokasi di Pulau Jawa merupakan salah satu instansi pemerintah yang saat ini sedang berusaha melakukan transformasi pelayanan untuk meningkatkan kepuasan pasien. Salah satu upayanya adalah dengan mengimplementasikan sistem informasi yang mengintegrasikan data kesehatan pasien dan sistem manajemen rumah sakit yaitu keuangan dan administrasi. Sistem informasi tersebut telah diimplementasikan sejak Januari 2019 untuk mendukung transaksi operasional setiap hari. Aplikasi ini diharapkan dapat berjalan dengan lancar, namun dalam tiga bulan terakhir (September - Desember 2019) berdasarkan dokumen daftar pengaduan terdapat 335 pengaduan dari pengguna. Salah satu keluhannya adalah dari unit rekam medis yang melaporkan riwayat kunjungan pasien pada aplikasi tidak sesuai dengan hasil yang diinginkan. Daftar sebaran pengaduan dari setiap subunit disajikan pada Tabel 1.

Tabel 1. Persentase Keluhan Pengguna 


\begin{tabular}{|l|c|l|c|}
\hline \multicolumn{1}{|c|}{ Unit } & \% Keluhan & \multicolumn{1}{c|}{ Unit } & \% Keluhan \\
\hline $\begin{array}{l}\text { Pendaftran } \\
\text { dan Rekam } \\
\text { Medis }\end{array}$ & $40 \%$ & Keuangan & $4 \%$ \\
\hline Rawat jalan & $20 \%$ & ICU & $14 \%$ \\
\hline Rawat Inap & $9 \%$ & $\begin{array}{l}\text { Ruang } \\
\text { operasi }\end{array}$ & $11 \%$ \\
\hline Farmasi/Obat & $7 \%$ & Lainnya & $4 \%$ \\
\hline
\end{tabular}

Banyaknya jumlah keluhan menunjukkan bahwa pengguna tidak puas dengan sistem[3]. Berdasarkan penelitian [4] dan [5], kepuasan pengguan merupakan indikator utama yang menunjukkan berhasil tidaknya sistem informasi. Wawancara pendahuluan dengan pengguna yang sedang menggunakan sistem aplikasi, salah satu dampak yang ditimbulkan oleh penerapan aplikasi adalah menurunnya aktivitas pengguna dan mempengaruhi waktu tanggap pasien serta menurunkan kepuasan pasien di RS XYZ.

Studi ini bertujuan untuk mengevaluasi faktor-faktor yang mempengaruhi pengguna dalam hal membantu meningkatkan efisiensi dan efektivitas dalam melakukan pekerjaannya di RS XYZ dengan menggunakan model Delone McLean IS Success dan memberikan rekomendasi untuk perbaikan aplikasi. Oleh karena itu, dirumusan pertanyaan penelitian adalah sebagai berikut:

1. Faktor-faktor apa saja yang mempengaruhi pengguna saat menggunakan aplikasi?

2. Perbaikan apa yang harus dilakukan oleh manajemen untuk meningkatkan penerapan aplikasi?

\section{LANDASAN TEORI \\ E-Government}

E-government berarti penggunaan TIK di lembaga pemerintah atau publik untuk meningkatkan dan mempromosikan layanan yang lebih efisien dan efektif kepada warganya [2][6][7].

\section{Sistem Informasi Kesehatan}

Sistem Informasi Kesehatan (SIK) adalah aplikasi yang fokus utamanya pada kebutuhan administrasi rumah sakit. Banyak rumah sakit telah menggunakan SIK untuk mengelola banyak aspek, yaitu klinis, finansial, dan administrasi. Berdasarkan Peraturan Menteri Kesehatan Republik Indonesia nomor 82 tahun 2013 disebutkan bahwa untuk mendukung fungsi badan pelayanan publik dalam meningkatkan efisiensi dan efektifitas operasional rumah sakit perlu diterapkan penerapan RIS[8].

\section{Model Sukses Delone McLean}

Model sukses Delone McLean merupakan model yang digunakan untuk mengukur tingkat keberhasilan dan efektifitas suatu sistem informasi dengan memberikan kerangka kerja yang komprehensif[14]. Model ini dipilih karena telah divalidasi[10], dan beberapa dimensi yang digunakan sesuai untuk aplikasi wajib seperti 
SIK di rumah sakit XYZ. Model tersebut disajikan pada Gambar 1.

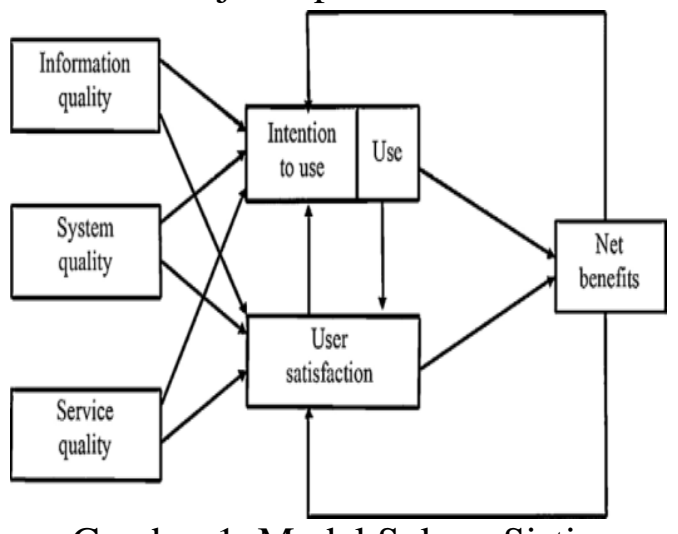

Gambar 1. Model Sukses Sistim Informasi

(Delone \& McLean, 2003)

\section{METODE PENELITIAN}

Studi ini menggunakan pendekatan campuran (mixed-method). Teknik penelitian kuantitatif dilakukan dengan penyebaran kuisioner dan didukung dengan studi dokumen perusahaan sebagai teknik kualitatif untuk memperoleh pemahaman yang lebih komprehensif terkait kondisi saat ini dan masalah yang dihadapi pengguna.

Tahapan metodologi penelitian ini adalah tahap identifikasi masalah, tahap analisis data, kesimpulan dan rekomendasi perbaikan seperti yang disajikan pada Gambar 2.

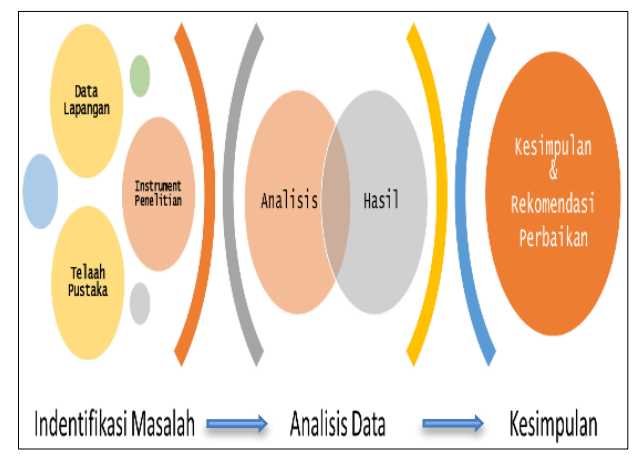

Gambar 2. Tahapan Penelitian

Pada identifikasi masalah, kami melakukan telaah Pustaka dan mengumpulkan data awal untuk mengetahui kondisi eksisting penggunaaan aplikasi SIK, hasil yang diharapkan oleh manajemen dan jumlah pengguna yang menggunakan KIS. Daftar indikator disusun berdasarkan dimensi dalam model konseptual. Kemudian kami menyusun kuesioner berdasarkan indikator.

Instrumen penelitian terdiri dari 25 item yang dirancang. Instrumen survei menjelaskan enam variabel: kualitas sistem, kualitas informasi, layanan, organisasi, kepuasan pengguna, dan manfaat. Setiap variabel berisi beberapa indikator yang diracik berdasarkan penelitian sebelumnya agar sesuai dengan penelitian saat ini; yang disajikan pada Tabel 2. Pengukuran item survei didasarkan pada skala tipe Likert lima poin yang berkisar dari "sangat tidak setuju" hingga "sangat setuju".

Tabel 2. Variabel \& Indikator

\begin{tabular}{|l|l|l|}
\multicolumn{4}{|c}{ Survey } \\
\hline Variabel \& Id & \multicolumn{1}{|c|}{ Indikator } & Ref \\
\hline Keamanan & Kelengkapan, Akurasi, Kekinian, & {$[14]$} \\
Informasi (KI) & Realibel, ketepatan waktu. & {$[15]$} \\
\hline $\begin{array}{l}\text { Kualitas Sistem } \\
(\mathrm{KS})\end{array}$ & Kemudahan, waktu respons, & {$[15][$} \\
& Keramahan antarmuka, Tingkat & $12]$ \\
& kesalahan layanan. & \\
\hline Kualitas & Dukungan teknis, Pelatihan, & {$[5][1$} \\
Layanan (KL) & respon yang bagus, Kompetensi. & $4]$ \\
& & {$[12][$} \\
& & $15]$ \\
\hline Organisasi (O) & Dukungan manajemen, Strategi, & {$[12]$} \\
& Komunikasi yang efektif. & \\
\hline
\end{tabular}




\begin{tabular}{|l|l|l|}
\hline Variabel \& Id & \multicolumn{1}{|c|}{ Indikator } & \multicolumn{1}{c|}{ Ref } \\
\hline Kepuasan & Keluhan dari pasien/pengguna. & {$[3][1$} \\
Pengguna (KP) & & $2]$ \\
\hline Keuntungan & Efektivitas, Efisiensi, Bermanfaat & {$[14][$} \\
Bersih (KB) & langsung & $12]$ \\
& & {$[15]$} \\
\hline Penggunaan & Cepat, hemat waktu dan hemat & {$[20]$} \\
Sistem (PS) & tenaga. & \\
\hline
\end{tabular}

Sampel yang digunakan dalam penelitian ini adalah seluruh karyawan yang menggunakan aplikasi SIK untuk menunjang aktivitasnya sehari-hari yang berjumlah 250 pengguna. Berdasarkan rumus Slovin dengan batas toleransi kesalahan 10\% maka total responden dalam penelitian ini adalah 75 responden. Kami membagikan kuesioner online kepada pengguna yang bertugas untuk melayani pasien secara langsung (perawat dan staf) dan kuesioner online didistribusikan ke pengguna backoffice. Dari semua kuesioner yang dibagikan, didapatkan 75 responden. Data yang telah terkumpul kemudian divalidasi dengan menggunakan uji validitas dan reliabilitas[12], kemudian dilakukan pengujian model konseptual dengan menggunakan analisis PLSSEM menggunakan software Smart PLS 3.0.

Model konseptual yang digunakan dalam penelitian ini mengacu pada Delone \& McLean IS Success[14], namun agar sesuai dengan penelitian saat ini karena manajemen telah mengamanatkan pengguna untuk menggunakan SIK, sehingga penggunaan sistem (actual use) dapat dievaluasi dari sudut pandang kegunaan[13]. Adapun perancangan model evaluasi SIK seperti disajikan pada Gambar 3.

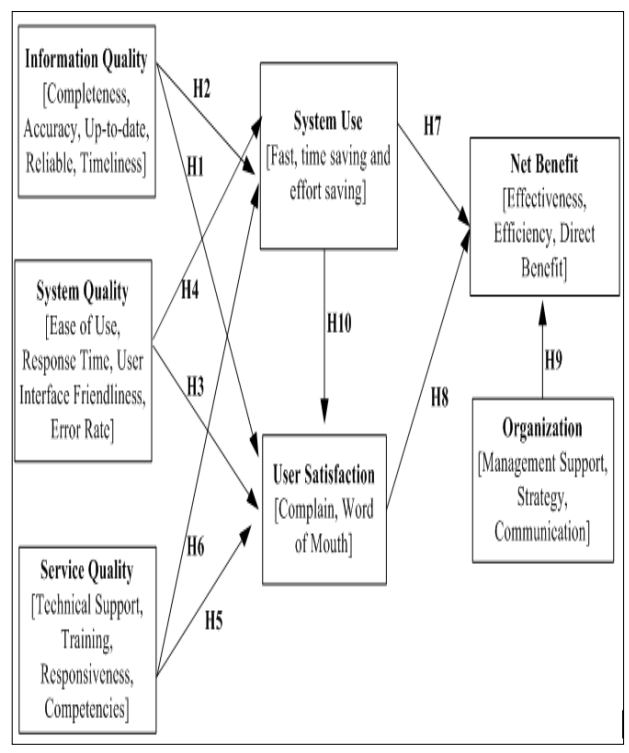

Gambar 3. Konseptual Model

Penelitian ini akan menguji hipotesis sebagai berikut:

$\checkmark$ H1: Kualitas Informasi (KI) berpengaruh positif signifikan terhadap Kepuasan Pengguna

$\checkmark$ H2: Kualitas Informasi (KI) berpengaruh positif signifikan terhadap Penggunaan Sistem

$\checkmark$ H3: Kualitas Sistem (KS) berpengaruh positif signifikan terhadap Kepuasan Pengguna

$\checkmark$ H4: Kualitas Sistem (KS) berpengaruh positif signifikan terhadap Penggunaan Sistem

$\checkmark$ H5: Kualitas Layanan (KL) berpengaruh positif signifikan terhadap Kepuasan Pengguna 
$\checkmark$ H6: Kualitas Layanan (KL) berpengaruh positif signifikan terhadap Penggunaan Sistem

$\checkmark$ H7: Penggunaan Sistem (PS) berpengaruh positif signifikan terhadap Manfaat Bersih

$\checkmark$ H8: Kepuasan pengguna (KP) berpengaruh positif signifikan terhadap Manfaat Bersih.

$\checkmark$ H9: Organisasi (O) berpengaruh positif signifikan terhadap Manfaat Bersih.

$\checkmark$ H10: Penggunaan Sistem (PS) berpengaruh positif signifikan terhadap Kepuasan Pengguna.

\section{HASIL DAN PEMBAHASAN}

\section{Data Responden}

Pengumpulan data melalui kuesioner online dari pengguna aplikasi SIK, kuesioner yang dibagi menjadi dua tahap. Tahap pertama tentang demografi responden dan tahap kedua tentang indikator konstruksi. Ada 25 pertanyaan terkait konstruk dan 2 pertanyaan terkait demografi responden. Demografi responden disajikan pada Tabel 4.

Tabel 3. Data Responden

\begin{tabular}{|c|l|r|}
\hline $\begin{array}{c}\text { Data } \\
\text { Responden }\end{array}$ & Keterangan & \multicolumn{1}{|c|}{$\begin{array}{c}\text { Persentase } \\
(\boldsymbol{\%})\end{array}$} \\
\hline \multirow{4}{*}{ Umur } & Tidak Ada & 1.37 \\
\cline { 2 - 3 } & $20-25$ & 20.55 \\
\cline { 2 - 3 } & $26-35$ & 54.79 \\
\cline { 2 - 3 } & $36-45$ & 18.55 \\
\cline { 2 - 3 } & $46-55$ & 2.74 \\
\hline Pendidikan & $\mathrm{D} 3$ & 54.42 \\
\cline { 2 - 3 } & $\mathrm{D} 4 / \mathrm{S} 1$ & 46.21 \\
\cline { 2 - 3 } & $\mathrm{S} 2 / \mathrm{S} 3$ & 2.37 \\
\hline
\end{tabular}

\section{Hasil Evaluasi dengan Model}

Hasil evaluasi dengan melakukan evaluasi outer model dan inner model. Outer model terdiri dari uji validitas dan uji reliabilitas. Untuk inner model terdiri dari R-square dan path coefficient untuk mengukur daya prediksi model.

Pengujian validitas terdiri dari validitas konvergen dan validitas diskriminan. Validitas konvergen berkaitan dengan prinsip bahwa indikator suatu konstruk harus sangat berkorelasi. Validitas konvergen dilakukan dengan menghitung loading factor dan Average Variance Extracted (AVE). Uji validitas diskriminan menyatakan bahwa indikator suatu konstruk seharusnya tidak berkorelasi tinggi dengan konstruk lain. Validitas diskriminan dilakukan dengan menghitung cross-loading indikator[17]. Nilai faktor loading indikator harus> 0,7 untuk lulus uji validitas konvergen [14]. Indikator yang memiliki nilai $\begin{array}{lllll}\text { antara } & 0.4 & \text { dan } & 0.7 & \text { dapat }\end{array}$ dipertahankan atau dihapus tergantung pengaruhnya terhadap nilai Composite Reliability (CR) atau AVE. Tabel 6 menunjukkan nilai factor loading dari masingmasing indikator final model[17].

Tabel 6. Nilai Loading factors

\begin{tabular}{|c|c|c|c|}
\hline Indikator & Nilai & Indikator & Nilai \\
\hline KI1 & 0.874 & PS01 & 0.929 \\
\hline KI2 & 0.890 & PS02 & 0.622 \\
\hline KI3 & 0.816 & PS03 & 0.868 \\
\hline KI4 & 0.708 & KP1 & 0.811 \\
\hline
\end{tabular}




\begin{tabular}{|l|l|l|l|}
\hline KL1 & 0.910 & KP2 & 0.708 \\
\hline KL2 & 0.721 & KP3 & 0.768 \\
\hline KL3 & 0.801 & OR1 & 0.551 \\
\hline KL4 & 0.784 & OR2 & 0.846 \\
\hline KS1 & 0.760 & OR3 & 0.939 \\
\hline KS2 & 0.748 & KB1 & 0.861 \\
\hline KS3 & 0.732 & KB2 & 0.741 \\
\hline KS4 & 0.574 & KB3 & 0.982 \\
\hline
\end{tabular}

Pada perhitungan iterasi validitas konvergen, kami membuang dua indikator: KS4, dan OR1, karena penghapusan indikator tersebut dapat meningkatkan nilai CR. Langkah selanjutnya adalah memeriksa nilai AVE. Menurut [17] nilai AVE harus> 0,5. Tabel 7 menunjukkan nilai AVE untuk semua variabel atau konstruk.

Tabel 7. Nilai AVE

\begin{tabular}{|l|c|l|}
\hline \multicolumn{2}{|c|}{ ID Nilai AVE } & \multicolumn{1}{|c|}{ Hasil } \\
\hline $\begin{array}{l}\text { Kualitas Informasi } \\
\text { (KI) }\end{array}$ & 0.736 & Diterima \\
\hline $\begin{array}{l}\text { Keuntungan Bersih } \\
\text { (KB) }\end{array}$ & 0.635 & Diterima \\
\hline Organisasi (O) & 0.887 & Diterima \\
\hline $\begin{array}{l}\text { Kualitas Layanan } \\
\text { KL) }\end{array}$ & 0.722 & Diterima \\
\hline $\begin{array}{l}\text { Kualitas Sistem } \\
\text { KS) }\end{array}$ & 0.717 & Diterima \\
\hline $\begin{array}{l}\text { Penggunaan Sistem } \\
\text { (PS) }\end{array}$ & 0.648 & Diterima \\
\hline $\begin{array}{l}\text { Kepuasan Pengguna } \\
\text { (KP) }\end{array}$ & 0.717 & Diterima \\
\hline
\end{tabular}

Langkah selanjutnya adalah melakukan pengujian reliabilitas dilakukan untuk mengetahui konsistensi indikator dalam merefleksikan variabel. Pengujian ini dilakukan dengan menghitung composite reliability (CR). Nilai CR harus> 0,70. Hasil $\mathrm{CR}$ diatas 0,70 untuk semua variabel yang berarti semua variabel tersebut reliabel seperti disajikan pada Tabel 8.

Tabel 8. Nilai CR dan Cronbach's Alpha

\begin{tabular}{|l|l|l|}
\hline ID & $\begin{array}{l}\text { Composite } \\
\text { Reliability }\end{array}$ & Cronbach's Alpha \\
\hline
\end{tabular}

\begin{tabular}{|l|l|l|}
\hline KI & 0.917 & 0.880 \\
\hline KB & 0.838 & 0.711 \\
\hline OR & 0.940 & 0.873 \\
\hline KL & 0.912 & 0.870 \\
\hline KS & 0.883 & 0.802 \\
\hline KP & 0.884 & 0.803 \\
\hline PS & 0.846 & 0.731 \\
\hline
\end{tabular}

Berdasarkan data pada Tabel 8 CR memiliki nilai> 0,7 yang berarti alat ukur yang digunakan dalam penelitian ini konsisten dan akurat untuk digunakan.

Langkah selanjutnya adalah pengujian koefisien jalur (path coefficient) untuk mengetahui hubungan yang signifikan antar variabel untuk membuktikan hipotesis apakah variabel tertentu berpengaruh signifikan terhadap variabel lain atau tidak. Variabel dianggap signifikan jika nilai koefisien jalur> 0,1 dan nilai $\mathrm{p}$ $<0,05$. Karena penelitian ini mengadopsi studi satu sisi maka bobot koefisiennya signifikan jika nilai t-statistik lebih besar dari 1.645 (sesuai taraf signifikansi 5\%) [18][19]. Hasil pengujian hipotesis disajikan pada Tabel 9.

Tabel 9. Hasil Pengujian Hipotesis

\begin{tabular}{|l|l|l|l|l|}
\hline \multicolumn{1}{|c|}{ ID } & $\begin{array}{c}\text { Path } \\
\text { Coefficient }\end{array}$ & $\begin{array}{c}\text { T- } \\
\text { Statistics }\end{array}$ & $\begin{array}{c}\text { P- } \\
\text { Value }\end{array}$ & Hasil \\
\hline $\begin{array}{l}\text { KI-KP } \\
\text { (H1) }\end{array}$ & 0.540 & 6.655 & 0.000 & Significant \\
\hline $\begin{array}{l}\text { KI-PS } \\
\text { (H2) }\end{array}$ & 0.413 & 4.007 & 0.001 & Significant \\
\hline $\begin{array}{l}\text { KS-KP } \\
\text { (H3) }\end{array}$ & 0.127 & 1.291 & 0.094 & $\begin{array}{l}\text { Not } \\
\text { Significant }\end{array}$ \\
\hline $\begin{array}{l}\text { KS-PS } \\
\text { (H4) }\end{array}$ & 0.413 & 5.793 & 0.000 & Significant \\
\hline $\begin{array}{l}\text { KL-KP } \\
\text { (H5) }\end{array}$ & 0089 & 1.324 & 0.093 & $\begin{array}{l}\text { Not } \\
\text { Significant }\end{array}$ \\
\hline $\begin{array}{l}\text { KL-PS } \\
\text { (H6) }\end{array}$ & 0.208 & 2.093 & 0.018 & Significant \\
\hline $\begin{array}{l}\text { KP-KB } \\
\text { (H7) }\end{array}$ & 0.455 & 3.262 & 0.001 & Significant \\
\hline $\begin{array}{l}\text { PS - KB } \\
\text { (H8) }\end{array}$ & 0.362 & 2.809 & 0.136 & Significant \\
\hline $\begin{array}{l}\text { OR-KB } \\
\text { (H9) }\end{array}$ & 0.292 & 2.737 & 0.041 & Significant \\
\hline
\end{tabular}




\begin{tabular}{|l|l|l|l|l|}
\hline $\begin{array}{l}\text { PS-KP } \\
(\text { H10 })\end{array}$ & 0.458 & 2.700 & 0.000 & Significant \\
\hline
\end{tabular}

A. Model Final

Setelah dilakukan analisis terhadap seluruh data yang terkumpul, didapatkan faktor-faktor apa saja yang berpengaruh signifikan terhadap keberhasilan penerapan SIK di RS XYZ. Model akhir dari penelitian ini dapat dilihat pada Gambar 4.

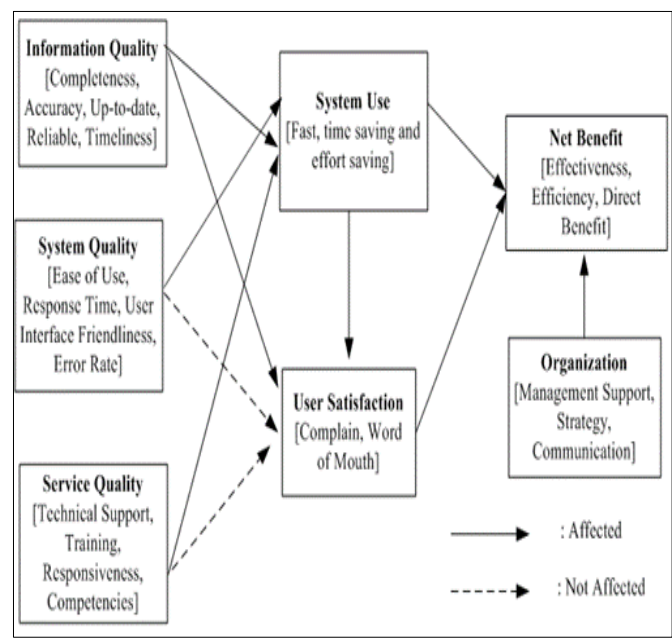

Gambar 4. Model Final

\section{KESIMPULAN DAN REKOMENDASI}

Aplikasi SIK digunakan untuk memberikan pelayanan administrasi kepada pasien. Hasil penelitian ini menemukan bahwa penggunaan sistem, kepuasan pengguna, dan organisasi akan mempengaruhi keuntungan bersih yang akan dirasakan oleh pengguna. Berdasarkan hasil penelitian ini kualitas informasi akan mendominasi kepuasan pengguna.

Adapun rekomendasi hasil penelitian adalah sebagai berikut:

Perbaikan kembali sistem informasi (SIK) yang dibutuhkan oleh setiap unit untuk menunjang pekerjaannya dan membuat ulang laporan berdasarkan kebutuhan pengguna.

Harus ada mengaudit data dalam database dan melakukan proses pengujian untuk mengetahui penyebab kesalahan dalam data yang ditampilkan dalam laporan.

Berdasarkan analisis, kualitas informasi pada SIK seperti ketidak lengkapan dan ketidaktepatan data dipengaruhi oleh fitur sistem yang tidak dapat diandalkan sehingga perlu dilakukan upgrade dari sisi fitur sistem.

\section{UCAPAN TERIMA KASIH}

Penulis mengucapakan bayak terima kasih kepada tim riset kepulauan digital Fakultas Teknik Unkhair.

\section{DAFTAR PUSTAKA}

[1]O. Al-Hujran, M. M. Al-Debei, A. Chatfield, and M. Migdadi, "The imperative of influencing citizen attitude toward $e$ government adoption and use," Comput. Human Behav., vol. 53, pp. 189-203, 2015.

[2]Y. Q. Zhu and A. Kindarto, "A garbage can model of government IT project failures in developing countries: The effects of leadership, decision structure and team competence," Gov. Inf. Q., vol. 33, no. 4, pp. 629-637, 2016.

[3]R. Vaezi, A. Mills, and W. Chin, "User Satisfaction with 
Information Systems: A

Comprehensive Model of Attribute-level Satisfaction," Commun. Assoc. Inf. Syst., no. April, pp. 165-206, 2019.

[4]R. Vaezi, A. Mills, and W. Chin, "User satisfaction with information systems: A comprehensive model of attribute-level satisfaction," Commun. Assoc. Inf. Syst., vol. 45, no. 1, pp. 165-206, 2019.

[5]A. L. Diar, P. I. Sandhyaduhita, and N. F. A. Budi, "The Determinant Factors of Individual Performance from Task Technology Fit and IS Success Model perspectives: a case of Public Procurement Plan Information System (SIRUP)," in 2018 International Conference on Advanced Computer Science and Information Systems (ICACSIS), 2018, pp. 69-74.

[6]M. A. Sarrayrih and B. Sriram, "Major challenges in developing a successful e-government: A review on the Sultanate of Oman," J. King Saud Univ. Comput. Inf. Sci., vol. 27, no. 2, pp. 230-235, 2015.

[7]R. Bilkova and A. Kralova, "Adoption model of mgovernment services," in 2017 International Conference on Information and Digital Technologies (IDT), 2017, pp. 52-55.

[8]Kementerian Kesehatan, "Peraturan Menteri Kesehatan Republik Indonesia Nomor 97 Tahun 2015 Tentang Peta Jalan Sistem Informasi Kesehatan Tahun
2015-2019," Peta Jalan Sist. Inf. Kesehat. Tahun 2015 2019, pp. 1-76, 2015.

[9]I. Ayebazibwe, H. C. Kimaro, and J. J. Kaasbøll, "System use and user satisfaction in the adoption of electronic medical records systems: A case of DHIS2 tracker implementation in Tanzania," in IFIP Advances in Information and Communication Technology, 2019.

[10]C. Bossen, L. G. Jensen, and F. W. Udsen, "Evaluation of a comprehensive EHR based on the DeLone and McLean model for IS success: Approach, results, and success factors," Int. J. Med. Inform., vol. 82, no. 10, pp. 940-953, 2013.

[11]L. Van Cauter, D. Verlet, M. Snoeck, and J. Crompvoets, "The explanatory power of the Delone \& McLean model in the public sector: A mixedmethod test," Inf. Polity, vol. 22, no. 1, pp. 41-55, 2017.

[12]L. M. Erlirianto, A. H. N. Ali, and A. Herdiyanti, "The Implementation of the Human, Organization, and Technology-Fit (HOT-Fit) Framework to Evaluate the Electronic Medical Record (EMR) System in a Hospital," Procedia Comput. Sci., vol. 72 , no. December, pp. 580 587, 2015.

[13]A. I. Ojo, "Validation of the Delone and McLean information systems success 
model," Healthc. Inform. Res., vol. 23, no. 1, pp. 60-66, 2017.

[14]W. H. DeLone and E. R. McLean, "The DeLone and McLean model of information systems success: A ten-year update," J. Manag. Inf. Syst., vol. 19, no. 4, pp. 9-30, 2003.

[15]D. R. Sadat, "M-Government Implementation Evaluation in Encouraging Citizen Participation in Indonesia: A Case Study of Lapor!," p. 100, 2014.

[16]J. B. Kouame, "Using Readability Tests to Improve the," J. Multidiscip. Eval., vol. 6, no. 14, pp. 132-139, 2010.

[17]A. Hair Joseph F (Kennesaw State University) Hult G Tomas M (Michigan State University) Ringle Christian M (Hamburg University of Technology, Germany and The University of Newcastle, Australia) Sarstedt Marko (Otto-von-Guericke University, Madeburg, Germany, "3b.HairBook2017PLS2ndEd.

(1).pdf," pp. 46-49, 2017.

[18]W. Abdillah and J. Hartono, "Partial Least Square (PLS) Alternatif Structural Equation Modeling (SEM) Dalam Penelitian Bisnis," Andi Offset, 2016.

[19]S. Guritno and H. Siringoringo, "Perceived Usefulness, Ease of use, and Attitude Towards Online Shopping Usefulness Towards Online Airlines Ticket Purchase," Procedia - Soc. Behav. Sci., vol. 81, pp. 212-216, 2013. 